Trivent Publishing

(C) The Authors, 2016

Available online at http://trivent-publishing.eu/

Engineering and Industry Series

Volume Power Systems, Energy Markets and Renewable Energy Sources in

South-Eastern Europe

\title{
Differential Protection Schemes and Techniques for Power Transformers - Educational Aspects
}

\author{
Nikolina Arapoglou, ${ }^{1}$ Kiriakos Siderakis ${ }^{2}$ \\ ${ }^{1}$ Department of Electrical Engineering Technological Educational Institute of Crete, \\ GR-71410 Heraklion, Crete, nikolina_arapoglou@ @otmail.com \\ ${ }^{2}$ HEDNO (Hellenic Electricity Distribution Network Operator S.A.)
}

\begin{abstract}
A simulation model for the study of the differential protection in the case of power transformers has been developed. In this direction MATLAB Simulink has been employed and the operation during fault has been investigated, in the case of a two phase fault for different windings connections. The simulation results reveal the influence of the delta winding connection, which limits the asymmetrical loading experienced.
\end{abstract}

\section{Keywords}

Differential protection; power transformers; non-symmetrical faults; simulink simulation

\section{Introduction}

Power Transformers are critical components of electric power systems. Difficult to repair on site and expensive to replace, they require reliable protection schemes, in order to ensure availability and fault free operation. One of the most 
widely used protection schemes for power transformers is the differential protection [1-3]. The operating principle of the differential protection scheme is in fact the first law of Kirchhoff considering the equivalent of a power transformer and the node introduced between the primary and secondary winding. Furthermore, the current flowing into the primary circuit should be equivalent to the current flowing in the secondary side, in a fault free condition [1-5].

What is critical in this case is the capability of the system to decide if a fault incident is inside the protection zone, thus in the transformer or outside [1]. In the first case, immediate operation of the protection system is required, in order to achieve operation reliability. On the other hand, if the experienced fault is not in the transformer, thus outside of the protection zone, no tripping action should be taken by the system. In this case, other protection systems will have to encounter the incident.

A special case that is also important is the energization period of the transformer [1-5]. During this time a difference between the primary and secondary currents is expected to take place and may be recognized by the system as an internal fault condition, operation that is not acceptable. Furthermore, the differential protection system must be able to recognize the energization current, known as inrush current and should not issue any tripping action.

Considering the importance of the differential protection systems, in the substation operation and reliability, it is necessary to include this issue in power system studies. In this direction, computer simulation programs can facilitate the investigation of the possible operation modes of a power transformer, in reference to the differential protection scheme. The first step is analysis of the transformer operation, in reference to the difference between the primary and secondary currents in the case of the various power system faults. In this paper, the results of this study, which is part of an ongoing research project in Crete, are presented.

\section{Differential protection and power system faults}

The differential protection scheme of a power transformer is illustrated in figure 1 [1-5]. The protection zone is established by the location of the current transformers. Furthermore, considering the zone limits, it is possible to distinguish internal and external outages.

Furthermore, the study must investigate three additional aspects. The first is the transformer windings connection, which can influence the distribution of 
currents in the two windings. In table 1, the winding connection types are illustrated, in the case of the power transmission system of Crete.

The second issue is the type of system fault. Four basic types are recognized, i.e. three-phase ( $3 \mathrm{ph}$ ) fault, two-phase ( $2 \mathrm{ph}$ ) fault, two-phase with ground ( $2 \mathrm{ph}$ g) fault and single-phase (1ph) fault [6]. Finally, the third issue is transformer loading, including the operation of the On Load Tap Changer (OLTC) [1].

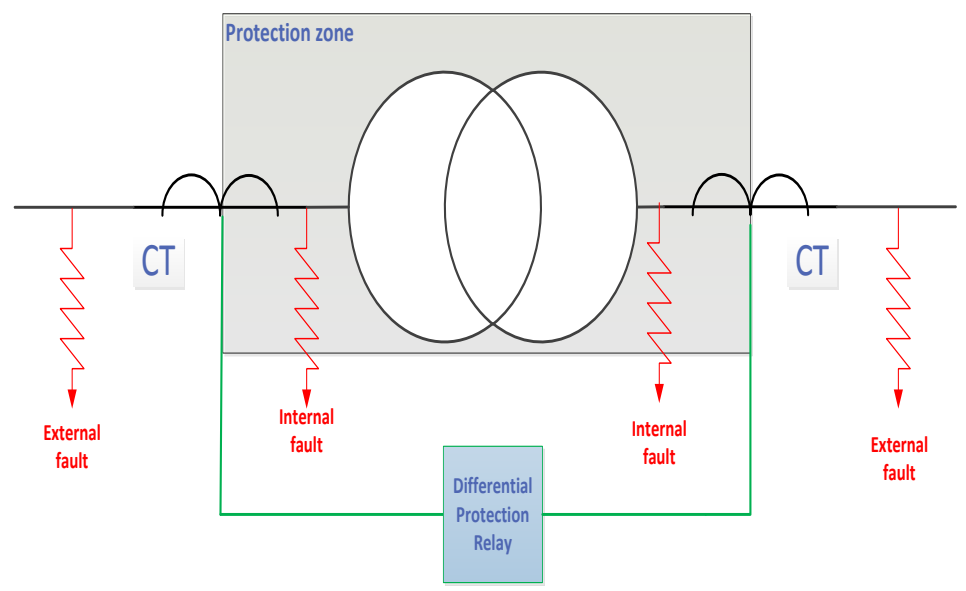

Fig. 1. Protection zone in a transformer differential protection scheme.

Table 1. Winding connections of the power transformers in Crete.

\begin{tabular}{|r|c|c|}
\hline & $\begin{array}{c}\text { Windings } \\
\text { Connection }\end{array}$ & $\begin{array}{c}\text { Number of } \\
\text { transformers }\end{array}$ \\
\hline 1 & $\mathrm{Y}-\mathrm{y}$ & $2(3.2 \%)$ \\
\hline 2 & $\mathrm{D}-\mathrm{y}$ & $35(56.5 \%)$ \\
\hline 3 & $\mathrm{Y}-\mathrm{d}$ & $19(30.6 \%)$ \\
\hline 4 & $\mathrm{Y}-\mathrm{z}$ & $6(9.7 \%)$ \\
\hline
\end{tabular}

For the simulations necessary within this study, MATLAB was selected and especially the Power System Blockset included in Simulink [7]. Many advantages concluded in this selection, as for example the availability of models in Simulink, the fact that many users in the field utilize this tool in their work, the available literature and the well-documented user interface [8-12]. The simulation setup implemented is illustrated in figure 2. 


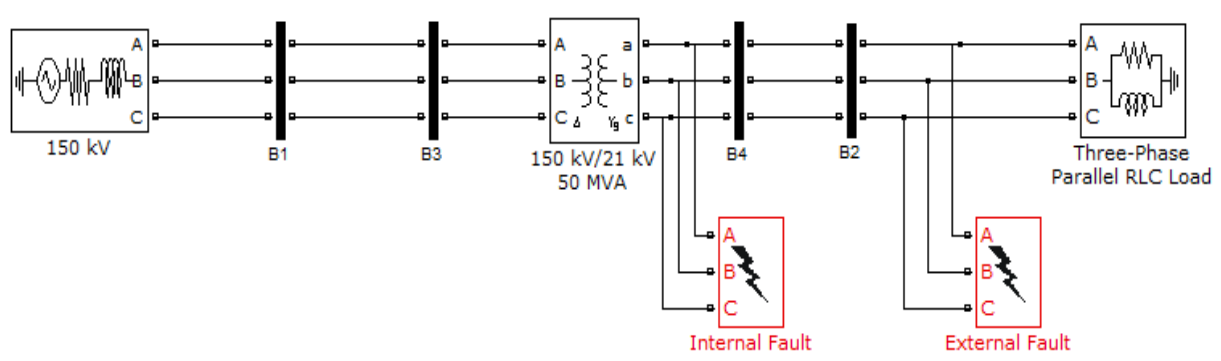

Fig. 2. Protection zone in a transformer differential protection scheme

\section{Fault tests in various transformer connections}

In the case of a fault, increased phase currents are experienced within the transformer. If the magnetic circuit participates in the fault loop, the windings connection can be critical for the operation of the differential protection. Considering a three-phase fault, due to the balance experienced between phases, no problems are due to appear. However, this is not the case in asymmetrical faults and this is an issue that has to be clarified. In this direction, the operation of a transformer in the case of an asymmetrical fault is simulated, for three different windings sets and a two-phase fault.

\section{A. Power transformer with D-Yg windings}

As it is shown in the figure 3, the model consists a three phase source of $150 \mathrm{Kv}$, a two windings step down power transformer $150 / 21 \mathrm{Kv}$, and a three phase load with active power of $8 \mathrm{MW}$ and reactive power of $6 \mathrm{MVar}$.

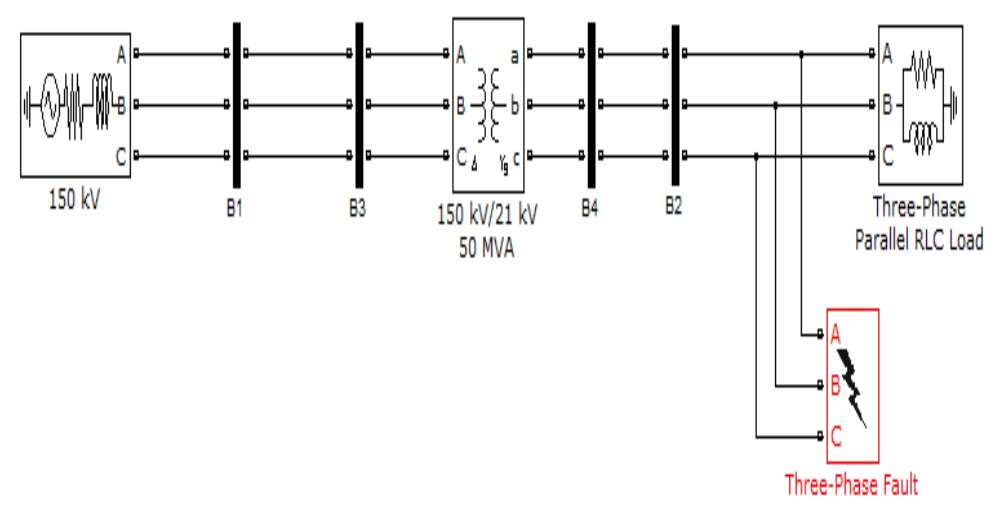

Fig. 3. First model with D-Yg transformer. 
The transformer model setup was based on the data of the typical three-phase power transformer in the power system of Crete. Figure 3,4 (Fig. 3, Fig.4) shows the subsystem block that we used in order to evaluate the phase current and voltage waveforms before and after the transformer during a two phase fault. The considered data are illustrated in figure 4.

For the fault simulation, the fault model included in the Simulink Power System Blockset was implemented. For the simulation a time frame of 0,2 sec was selected and a two-phase fault between phases A and B was applied for a time period of $0,15 \mathrm{sec}$. The current waveforms for the currents of each phase, before and after the transformer, are illustrated in figures 5, 6 and 7 .

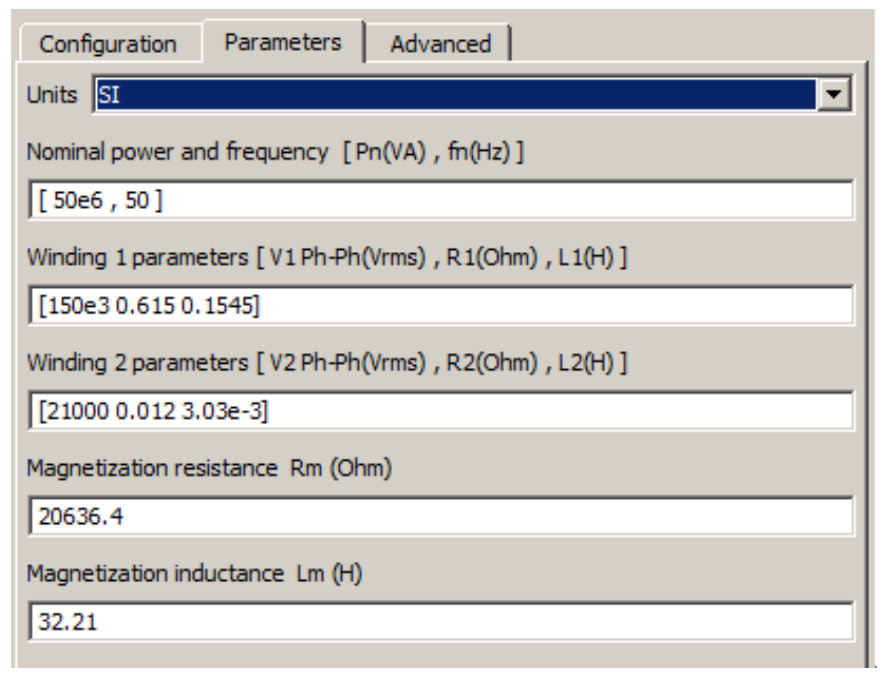

Fig. 4. Block parameters window of the transformer

In addition the phase to ground voltage for high voltage (HV) and low voltage (LV) side respectively are illustrated in figures 8,9 and 10 . 


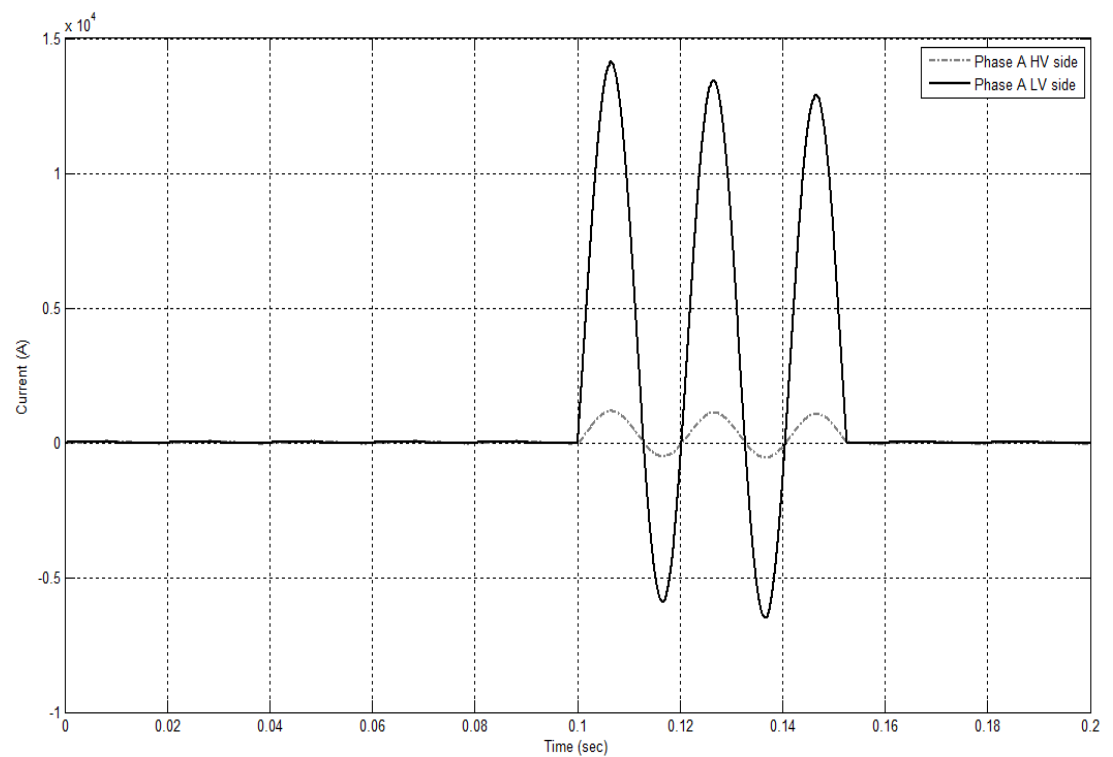

Fig. 5. Current of phase A on HV, LV side

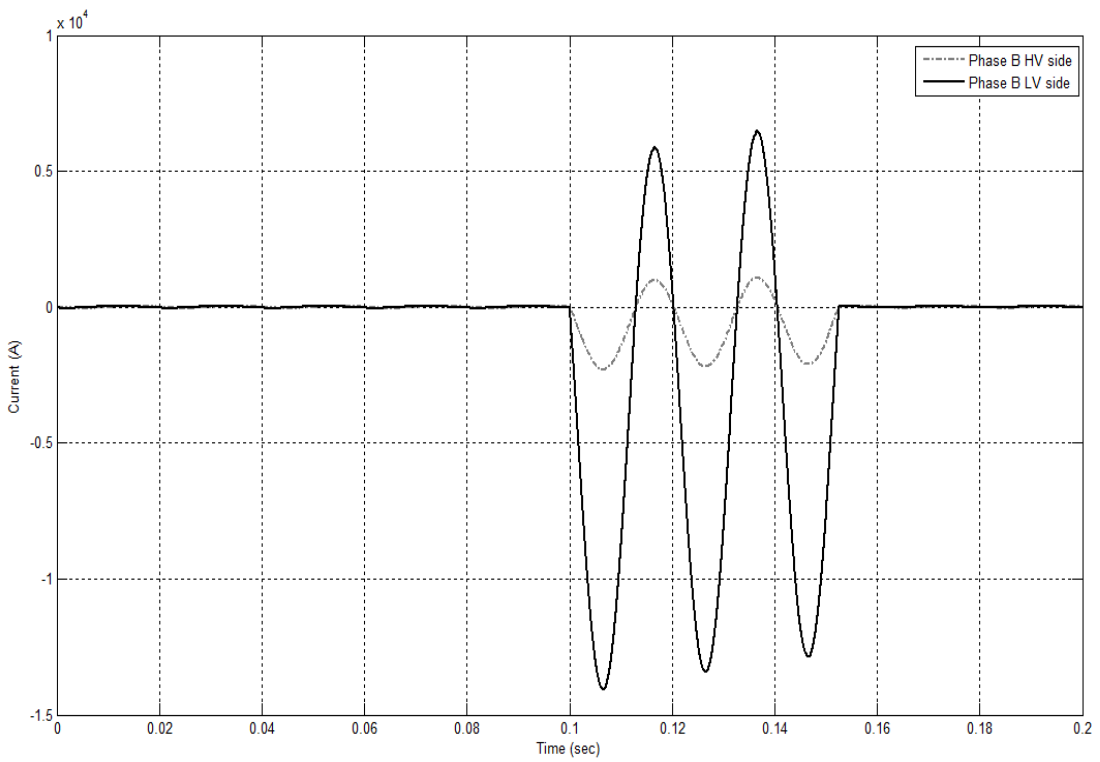

Fig. 6. Current of phase B on HV, LV side 


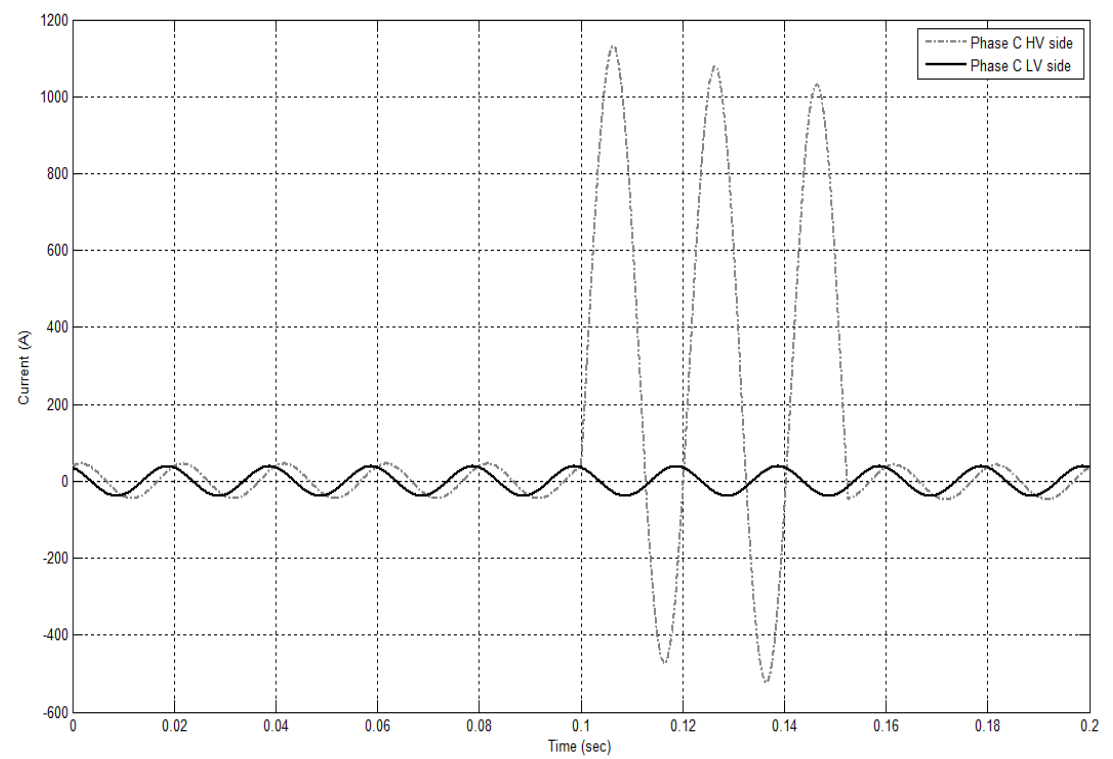

Fig. 7. Current of phase C on HV, LV side

The currents in the secondary winding are typical for a two-phase fault. The two participating phases, demonstrate currents of the same level and opposite phase. Further the current in the third "clear" phase is not influenced by the fault. However this is not that case in the primary side, where due to the Delta connection a current is evident also in the "clear" phase, thus can be seen as a non-symmetrical three-phase fault. 


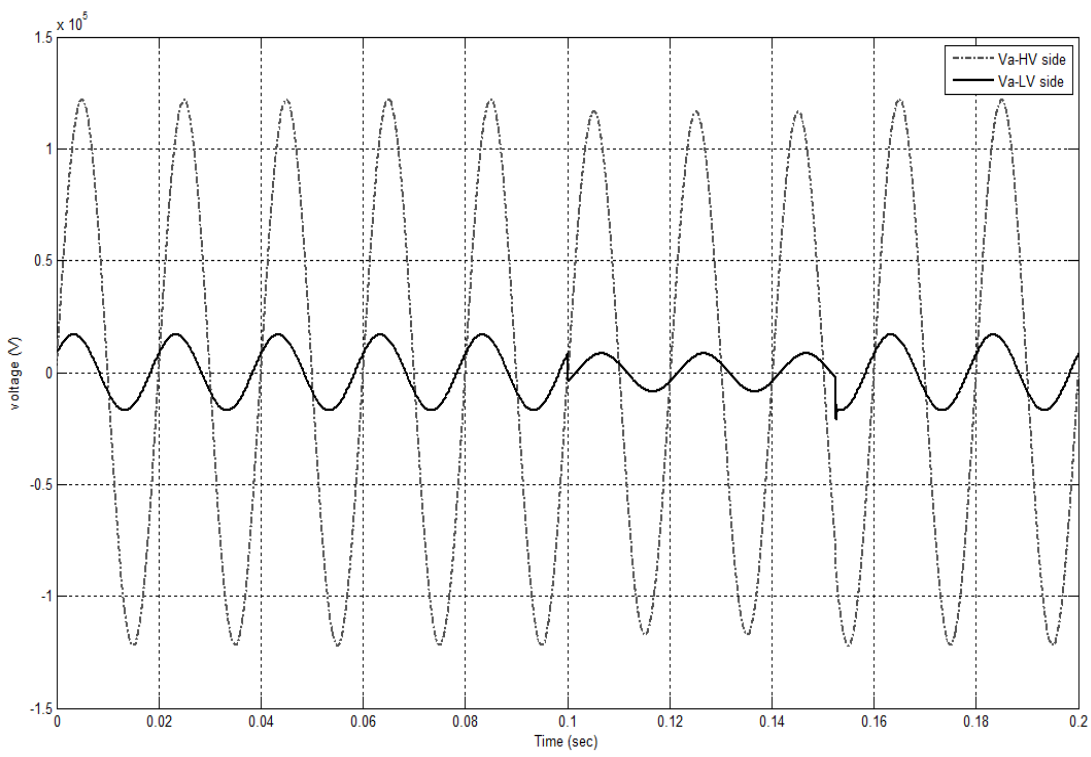

Fig. 8. Phase voltage A

Regarding the voltage, a drop on the side experiencing the fault is evident at the beginning and at the end of the fault for both phases A and B. In addition, incidents of voltage reversals are also evident at the beginning and at the end of the fault. No remarkable changes can be seen in the primary side, as far as the voltage is concerned.

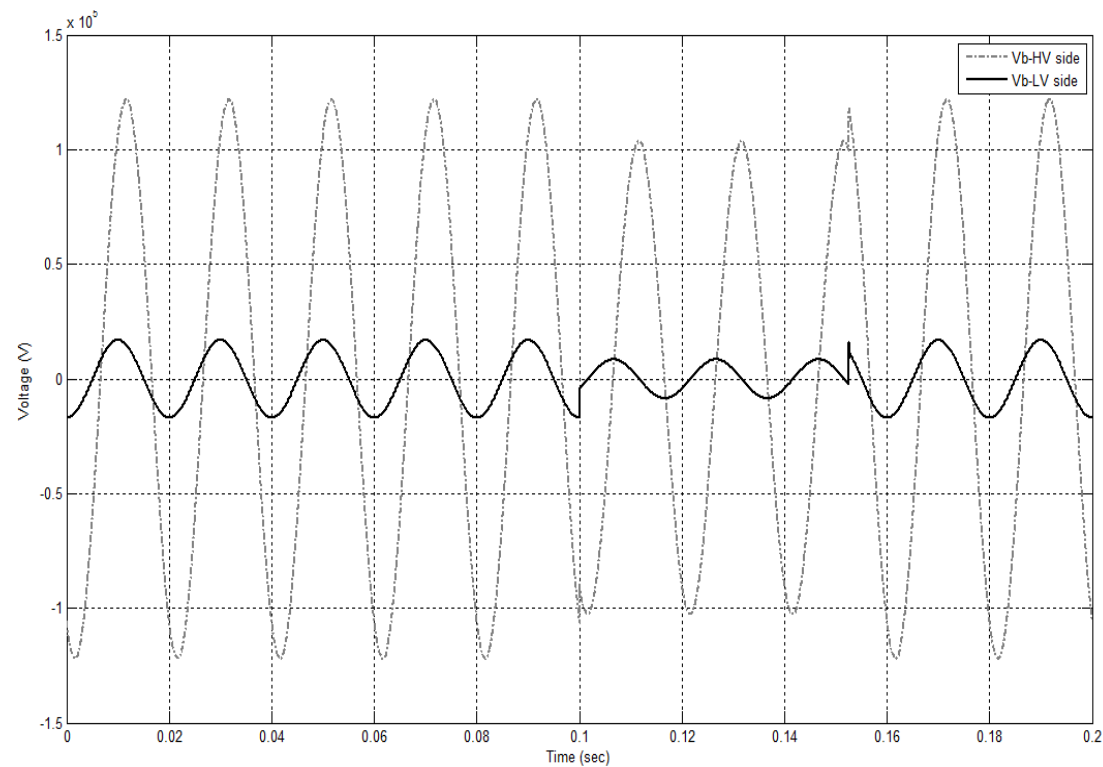

Fig. 9. Phase voltage B 


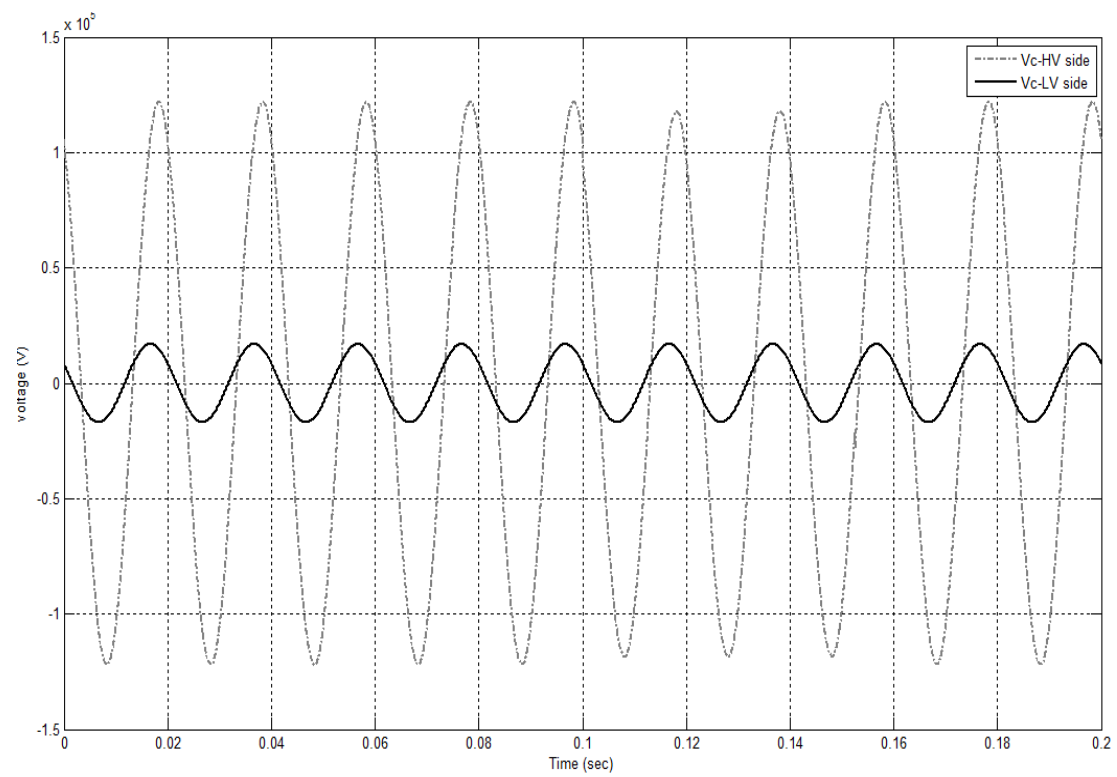

Fig. 10. Phase voltage $C$

\section{B. Power transformer with $Y g-D$ windings}

For the same fault conditions and duration and similar winding connection, the operation is investigating for the opposite power flow direction. The waveforms for the currents of each phase, before and after the transformer, are illustrated in figures 11,12 and 13. In addition the phase to ground voltage for high voltage (HV) and low voltage (LV) side respectively are illustrated in figures 14, 15 and 16. 


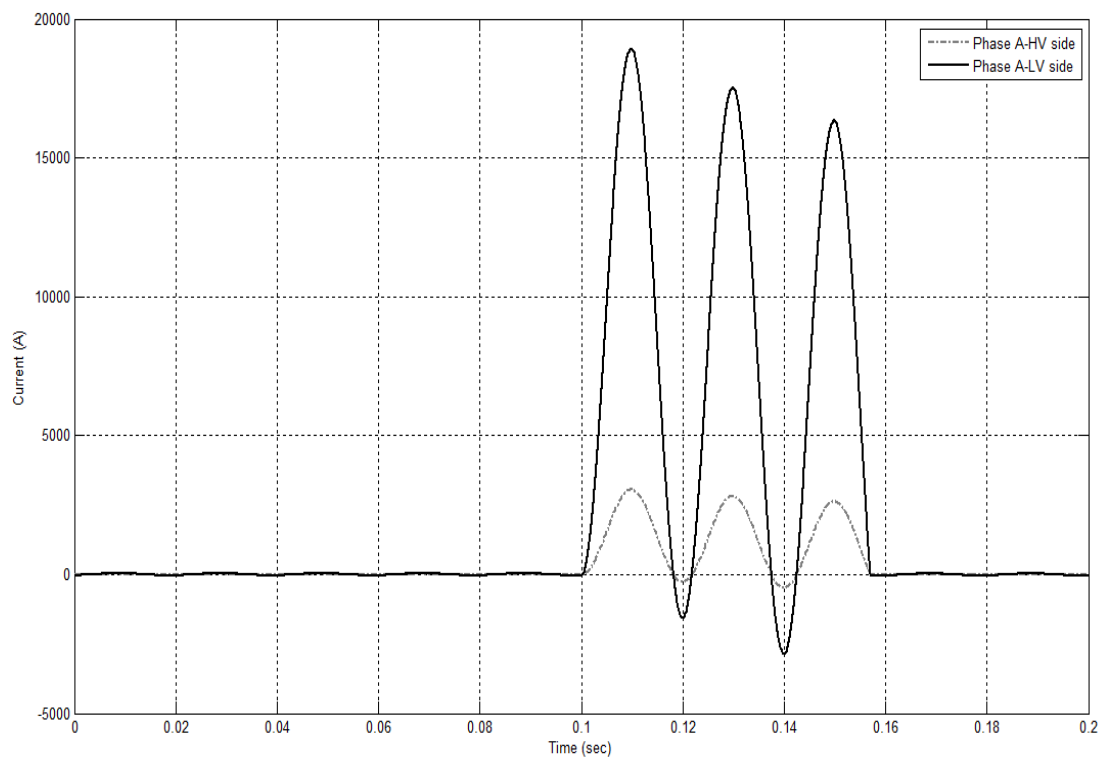

Fig. 11. Current of phase A on HV, LV side

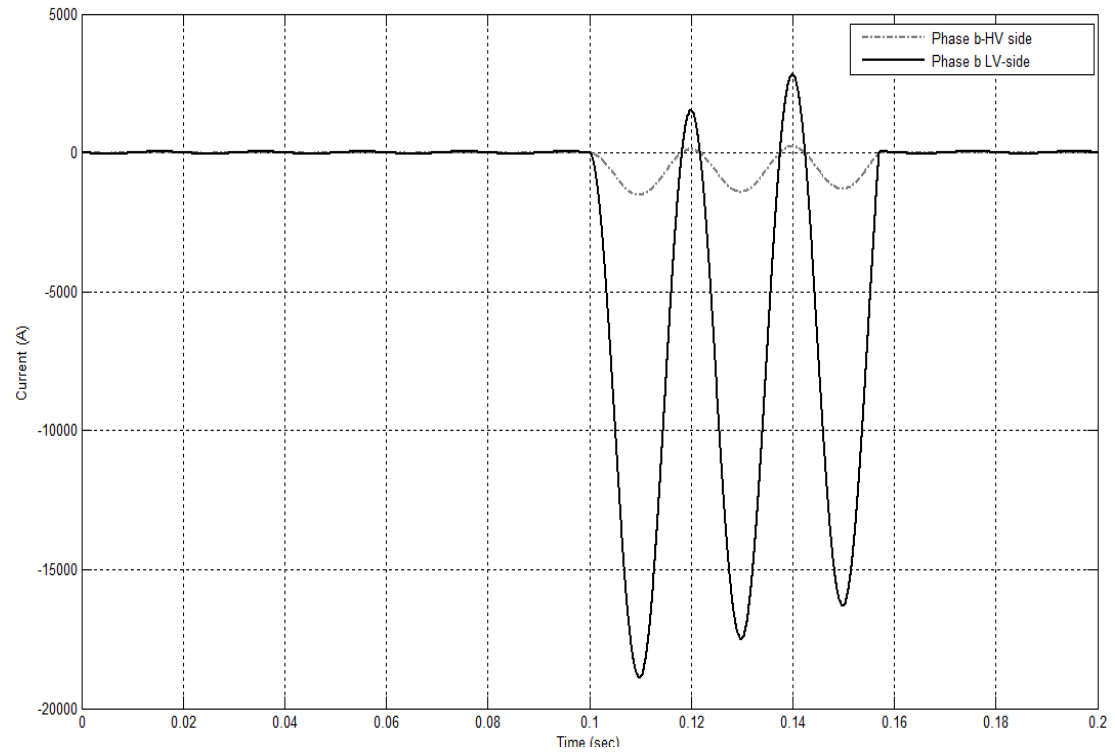

Fig. 12. Current of phase $B$ on HV, LV side 


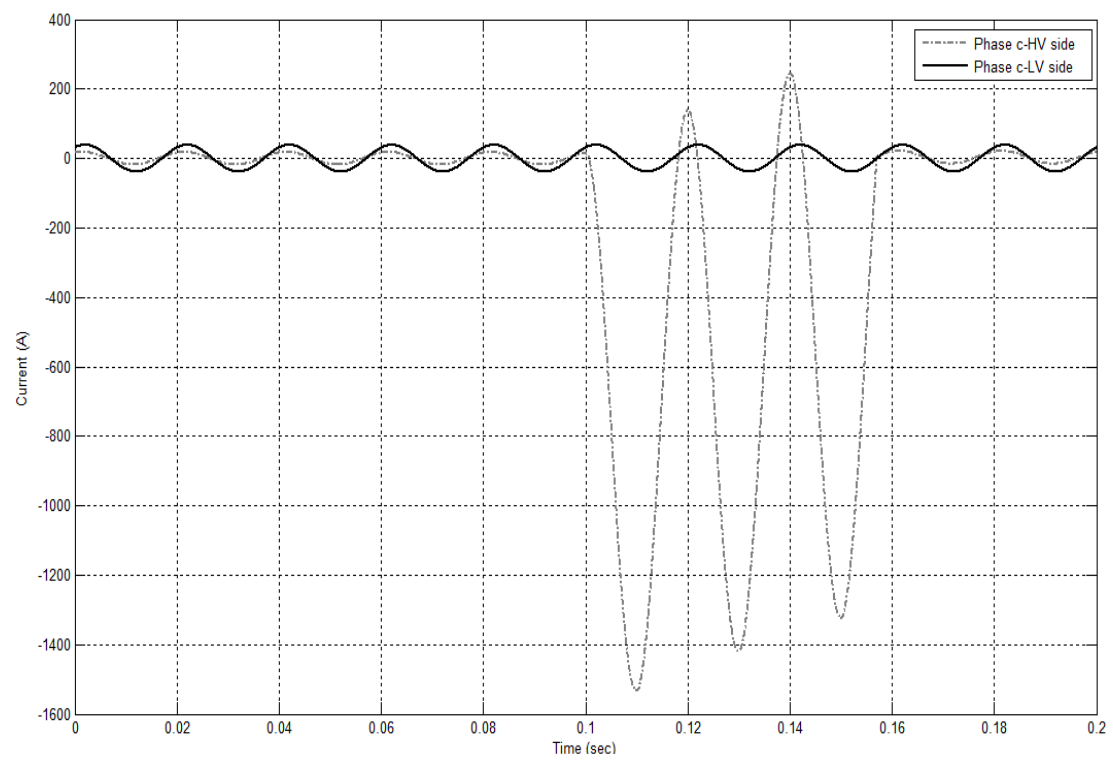

Fig. 13. Current of phase C on HV, LV side

In this case also the currents in the secondary winding are typical for a twophase fault. The two participating phases, demonstrate currents of the same level and opposite phase. Further the current in the third "clear" phase is not influenced by the fault. In the primary side, although it is connected in Y setup, a current is evident also in the "clear" phase. This is similar behavior to the previous case and it is evident due to the presence of the delta winding. 


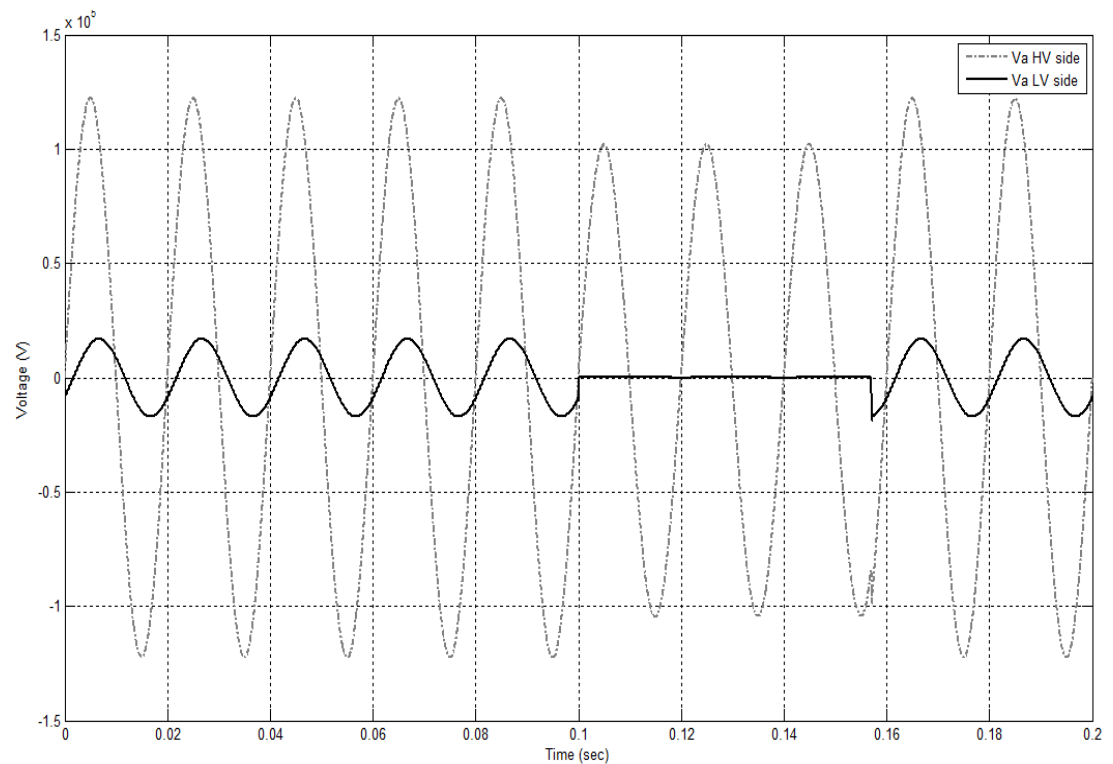

Fig. 14. Phase voltage A

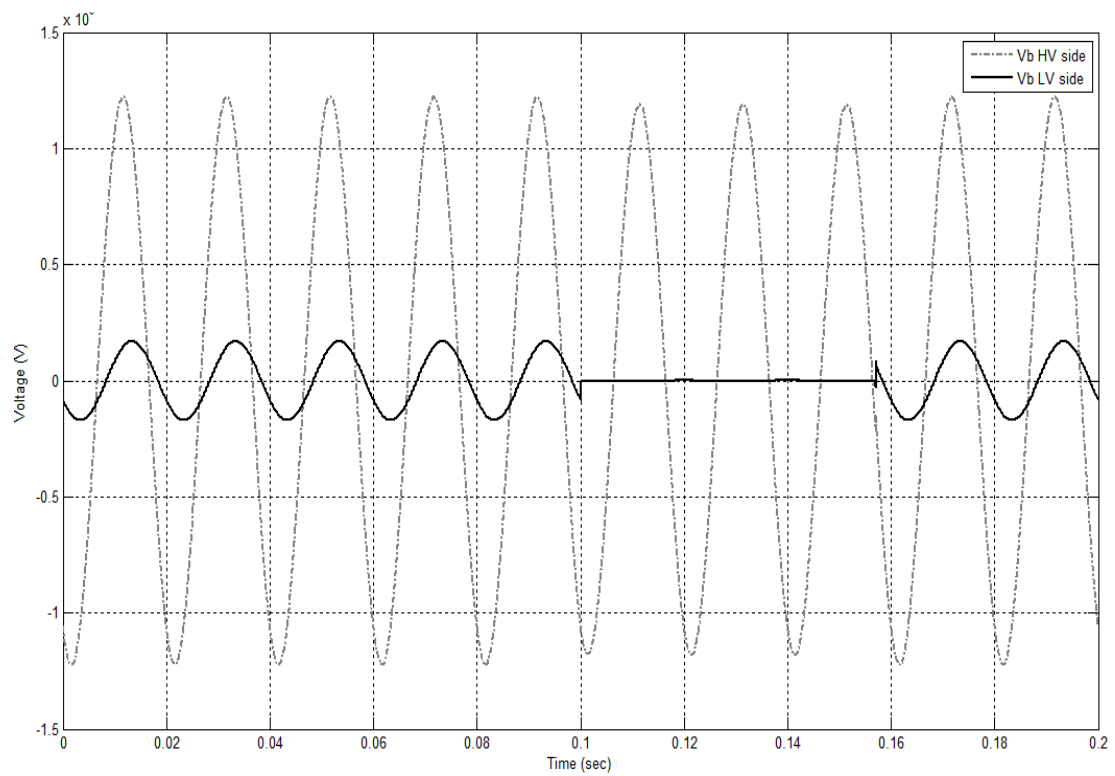

Fig. 15. Phase voltage $B$ 


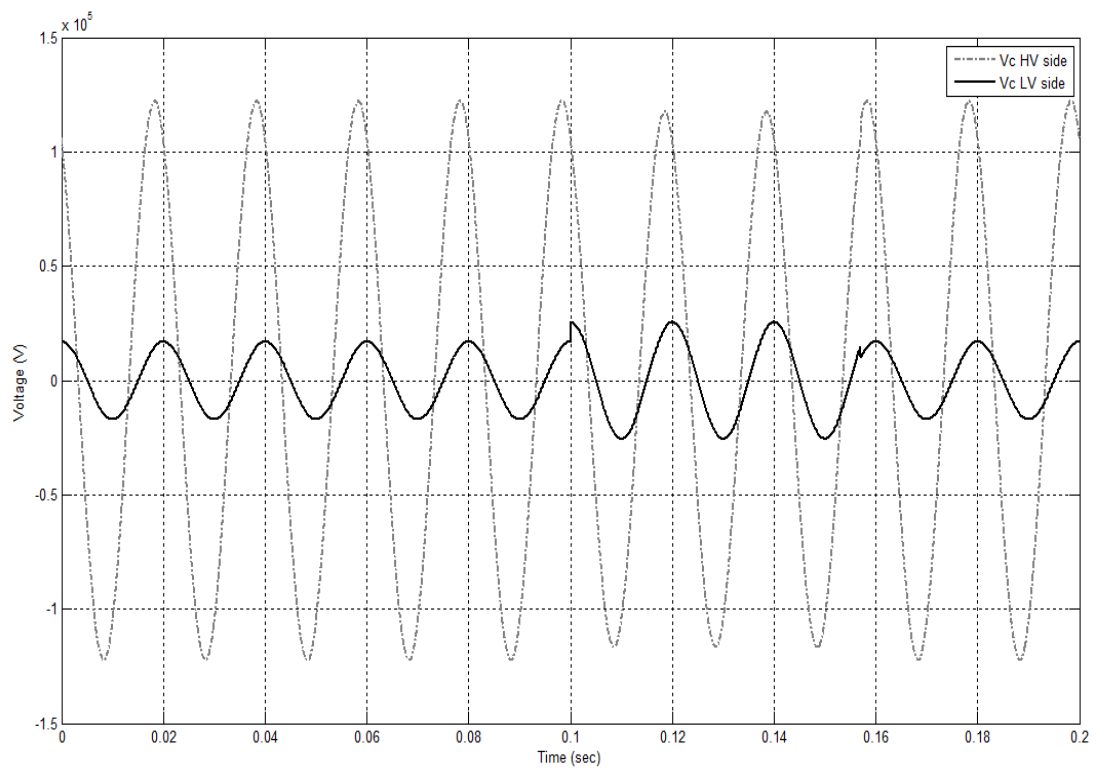

Fig. 16. Phase voltage $C$

As far as the voltage is concerned, there are differences in this case. Due to the fault, the voltage on the faulted phases is zero and in the same time an overvoltage is observed in the third "clear" phase.

\section{Power transformer with $Y-Y$ windings.}

For the same fault conditions and duration but different winding connection, the operation is investigated. The waveforms for the currents of each phase, before and after the transformer, are illustrated in figures 17, 18 and 19. In addition the phase to ground voltage for high voltage (HV) and low voltage (LV) side respectively are illustrated in figures 20,21 and 22 .

In this case also the currents evident on both sides are typical for a two-phase fault. The two participating phases, demonstrate currents of the same level and opposite phase. Further the current in the third "clear" phase is not influenced by the fault. Therefore the absence of the delta winding is the reason that the type of fault which is the same for both sides. Further the same are valid as far as the voltage is concerned and only voltage reversal incidents can be found at the beginning and end of the fault. 


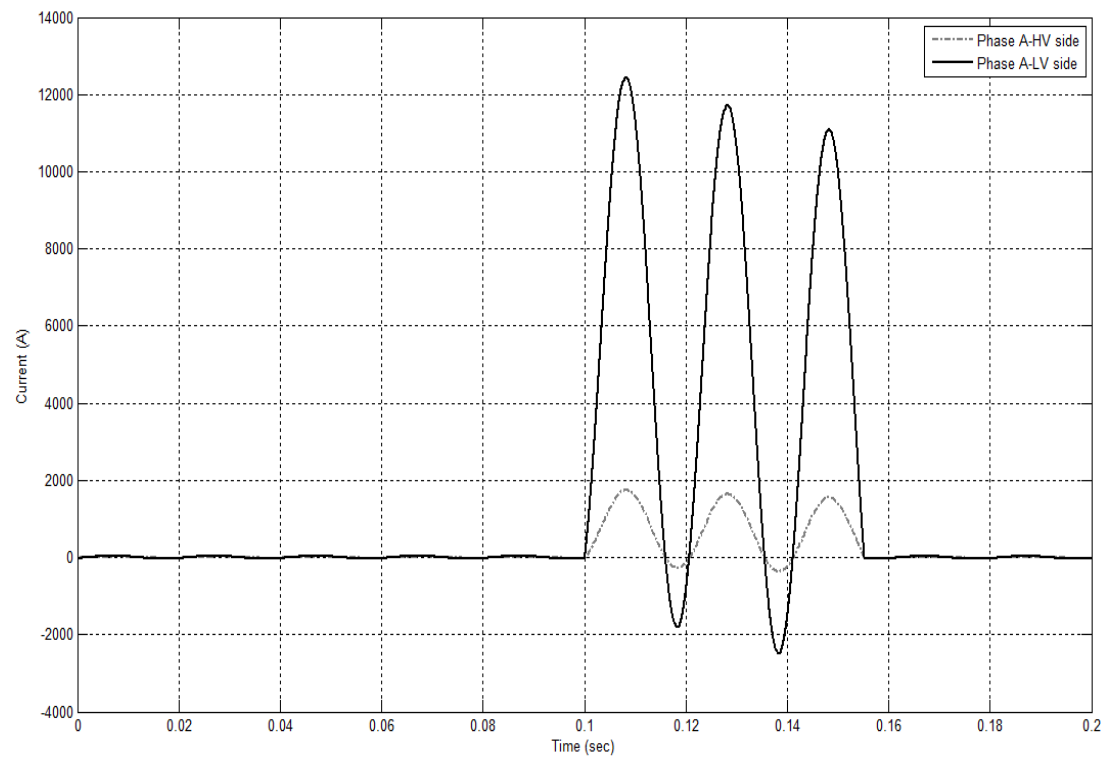

Fig. 17. Current of phase A on HV, LV side

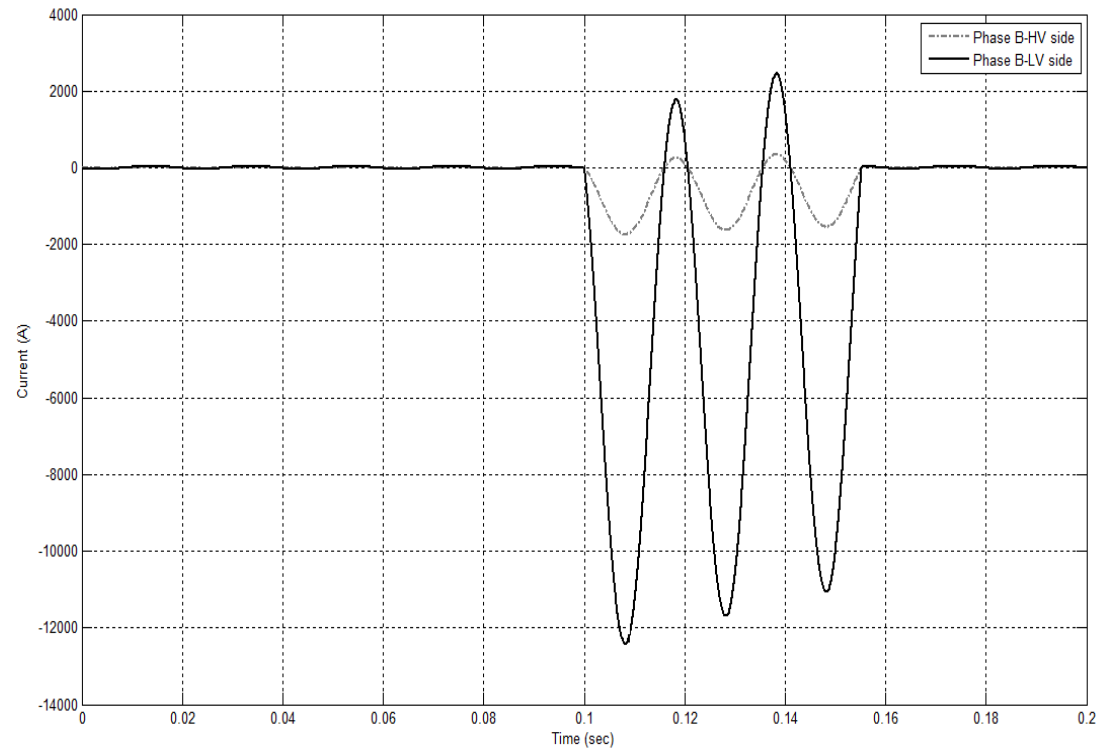

Fig. 18. Current of phase B on HV, LV side 


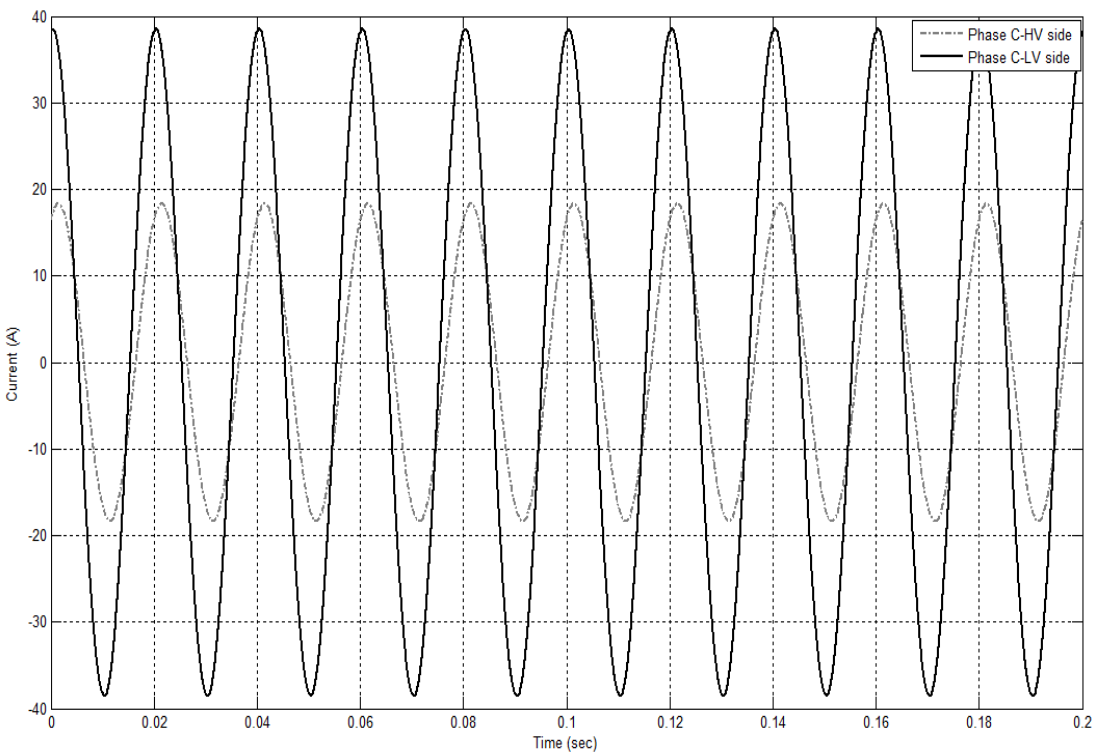

Fig. 19. Current of phase $\mathrm{C}$ on $\mathrm{HV}$, LV side

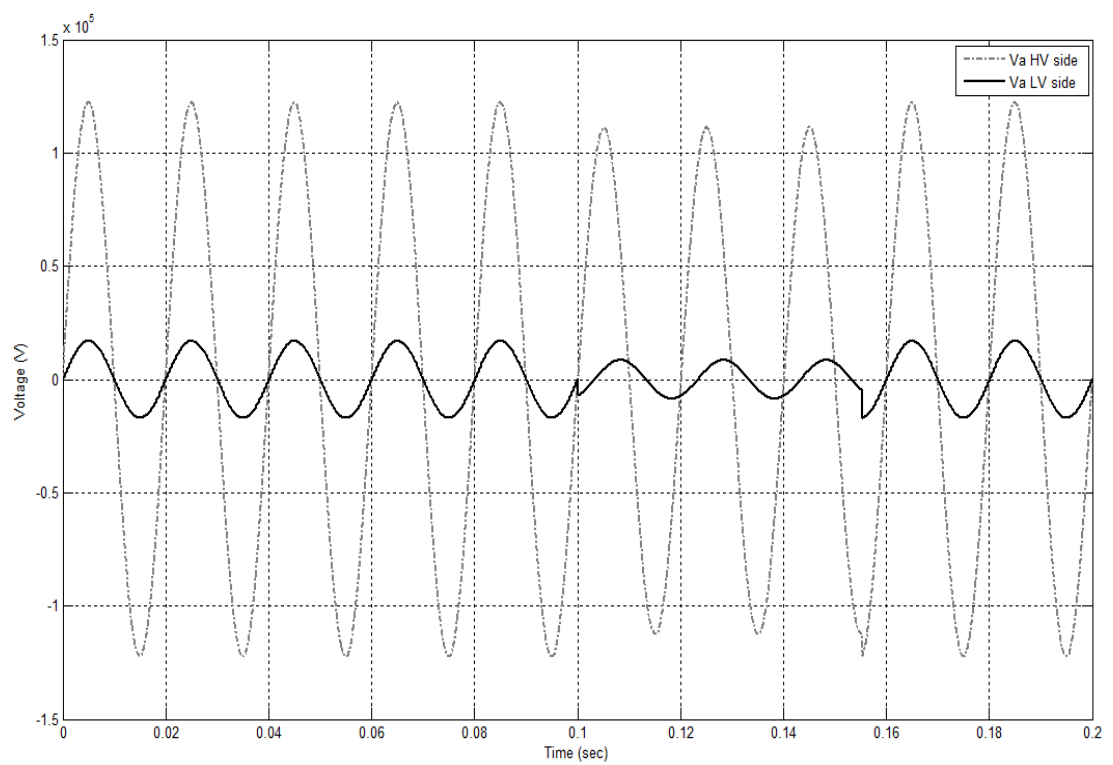

Fig. 20. Phase voltage A 


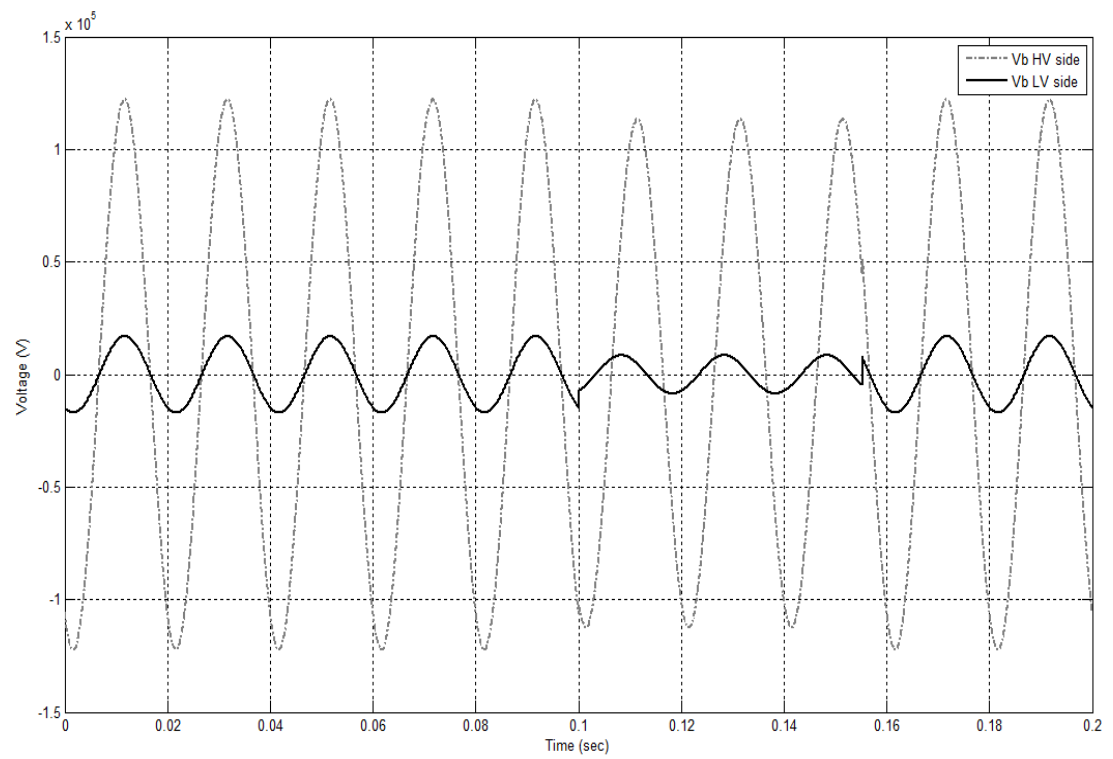

Fig. 21. Phase voltage B

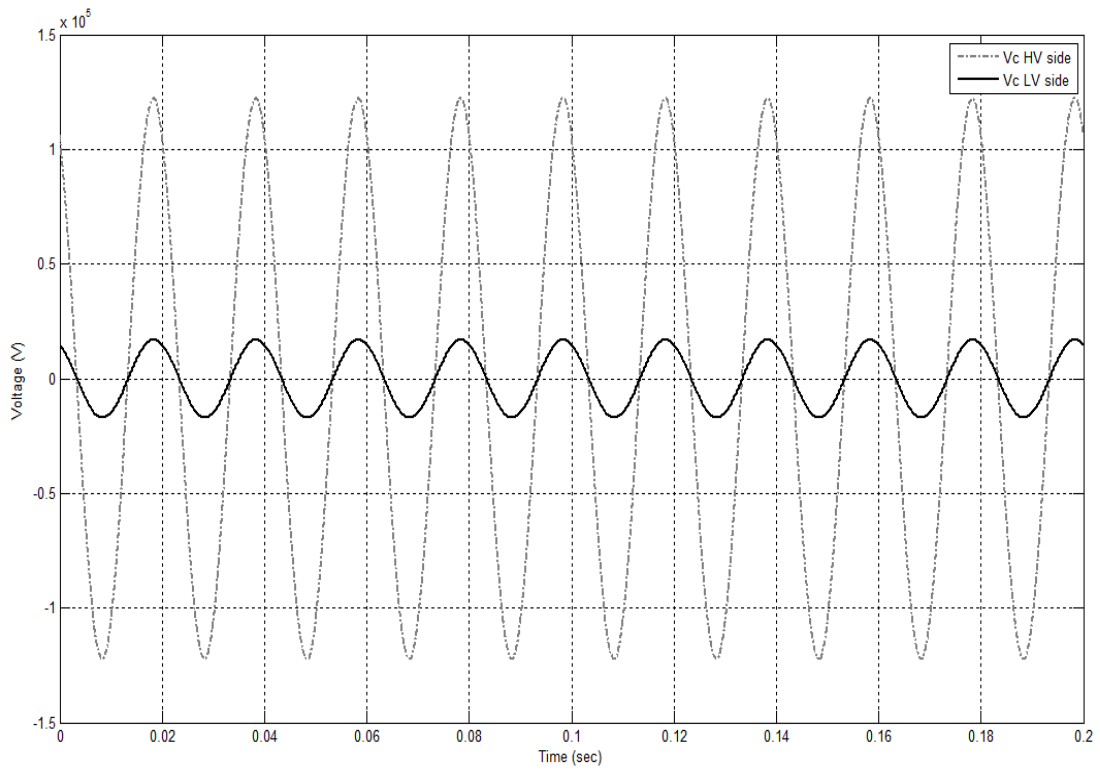

Fig. 22. Phase voltage $C$ 


\section{Conclusion}

Differential protection is a critical system for the reliable operation of a substation. In order to develop the knowledge of the transformer operation, within the scope of academic studies, Simulink has been utilized, in order to provide an efficient simulation tool. The transformer model and case studies are developed according to data available in the power system of Crete. Further, the operation of the transformer in the case of a two phase was investigated, for different winding connections. The simulation results illustrate the importance of the delta connection, which decreases the degree of asymmetrical loading from the secondary to the primary winding. Finally, the developed model can incorporate also measuring systems and control units to form a complete differential protection model.

\section{References}

[1] Ziegler, Gerhard, "Numerical differential protection: principles and applications", $2^{\text {nd }}$ Edition, Publicis Pub.

[2] A.T. Johns, S.K. Salman, "Digital Protection for Power Systems", The IEE Power Series 15.

[3] C. Christopoulos, A. Wright . "Electrical Power System Protection", Springer US, 1999.

[4] P.M. Anderson "Power System Protection, The IEEE Series on Power Engineering”, Wiley - IEEE Press, 1998.

[5] J.J. Winders, "Power transformers: principles and applications", Marcel Dekker, 2002.

[6] Mohamed A. Ibrahim, "Disturbance Analysis for Power Systems", Wiley IEEE Press, 2011.

[7] Power system blockset user's guide, The math works, Version 2.

[8] P.B.Thote, M.B. Daigavane, N.G. Bawane, "Matlab simulink based digital protection of transformer", International Journal of Research in Engineering and Technology Volume: 03 Issue: 02, Feb-2014.

[9] Ihedioha Ahmed C., "Differential Protection for Power Transformer Using Relay", International Journal of Trend in Research and Development, Volume 3(1) Jan-Feb 2016.

[10] Harjit Singh Kainth, Gagandeep Sharma, "A New method for differential protection in Power transformer", Journal of Electrical and Electronics Engineering, Volume 9, Issue 2 Ver. IV (Mar - Apr. 2014), 64-70. 
[11] Behrooz Vahidi, Vahid Farahani, "Modelling and simulation the current transformers for measuring current harmonics using Matlab-Simulink" ,international review of modelling and simulations, Volume 4, N.4 (August 2011).

[12] Harish Balaga, Neha Gupta Devendra Nath Vishwakarma, "GA trained parallel hidden layered ANN based differential protection of three phase power transformer", Electrical power and energy systems, Volume 67, (May 2015), 286-297. 